\title{
Pseudomembranous colitis in a leukaemia unit: a report of five fatal cases
}

\author{
D. W. MILLIGAN AND J. K. KELLY \\ From the Department of Clinical Haematology, Manchester Royal Infirmary, and the Department of \\ Pathology, University of Manchester, Manchester M13 9PT, UK
}

SUMMARY Five cases of clindamycin-associated pseudomembranous colitis in leukaemic patients are reported. These cases were all fatal, and it is suggested that the use of clindamycin in leukaemic patients should be reserved for specific indications.

Antibiotic-associated pseudomembranous colitis (PMC) is associated particularly with lincomycin and clindamycin (Tedesco et al., 1974). The aetiology of PMC was recently elucidated when toxin was identified in patients' stools (Larson et al., 1977; Larson and Price, 1977), and Clostridium difficile was shown to be the organism responsible (Bartlett et al., 1977; Bartlett et al., 1978a,b; George et al., 1978).

The mortality rate from PMC varies considerably -from $0 \%$ (Tedesco et al., 1974) to $44 \%$ (British Medical Journal, 1978) - and is highest in patients already seriously ill (Price and Davies, 1977). We report here five cases, all fatal, occurring in a haematology unit within the space of eight months.

\section{Case reports}

\section{CASE 1}

This 52-year-old woman had been diagnosed as having smouldering leukaemia one year previously. She remained in good health on prednisolone until admission with pyrexia, marked skin purpura, and vaginal bleeding.

Investigations: Haemoglobin $8.4 \mathrm{~g} / \mathrm{dl}$, white cells $3.8 \times 10^{9} / 1$, platelets $10 \times 10^{9} / 1$, serum albumin $28 \mathrm{~g} / \mathrm{l}$, serum potassium $3.8 \mathrm{mmol} / \mathrm{l}$. The bone marrow showed acute myeloblastic leukaemia (AML), and blood, throat, and urine cultures were negative.

She was started on intravenous tobramycin and clindamycin, which were continued for 10 days. On the third day she began cytotoxic chemotherapy with daunorubicin and cytosine arabinoside (Crowther et al., 1973). This exacerbated her thrombocytopenia, and platelet and blood transfusions were given.

Received for publication 18 June 1979
On the 18th hospital day she started a second course of daunorubicin and cytosine, and this resulted in a fall in the white cells to $0 \cdot 15 \times 10^{9} / \mathrm{dl}$. The next day she complained of severe abdominal pain, and the abdomen was distended with evidence of peritonism but at no time did she have diarrhoea. Concurrently with the development of abdominal pain she became febrile and was restarted on intravenous tobramycin and clindamycin. Her temperature remained elevated but serial blood cultures were negative. Severe abdominal pain, requiring intravenous pethidine, persisted, and an $x$-ray revealed a distended small bowel with multiple fluid levels compatible with an ileus.

On the 22nd hospital day the serum albumin was $26 \mathrm{~g} / \mathrm{l}$ and serum potassium was $3.9 \mathrm{mmol} / \mathrm{l}$. Blood cultures grew Escherichia coli. On the 27th hospital day she lapsed into unconsciousness and died.

At necropsy the principal findings were skin and serosal purpura, marrow histology consistent with AML, submucous uterine leiomyomata, oesophagitis, small pleural effusions, 2 litres of bloodstained ascites, and PMC. The colon was distended and boggy, and the serosa was blackened by haemorrhage. The mucosal surface was studded with yellowish, firm plaques, $0 \cdot 2-4 \cdot 0 \mathrm{~cm}$ in diameter, which were raised above the surrounding healthy mucosa by extreme submucosal oedema, and the severity of the lesions diminished distally (Figs 1 and 2). Adherent mucus was not present.

Microscopically the lesions showed the range of findings described by Goulston and McGovern (1965) and were mainly types II and III of Price and Davies (1977) with partial or full thickness necrosis of the mucosa, glandular hypersecretion, and pseudomembranes composed of fibrin, mucus, and inflammatory cells. The quantity of fibrin in the pseudomembranes in this case, as shown in Martius Scarlet 


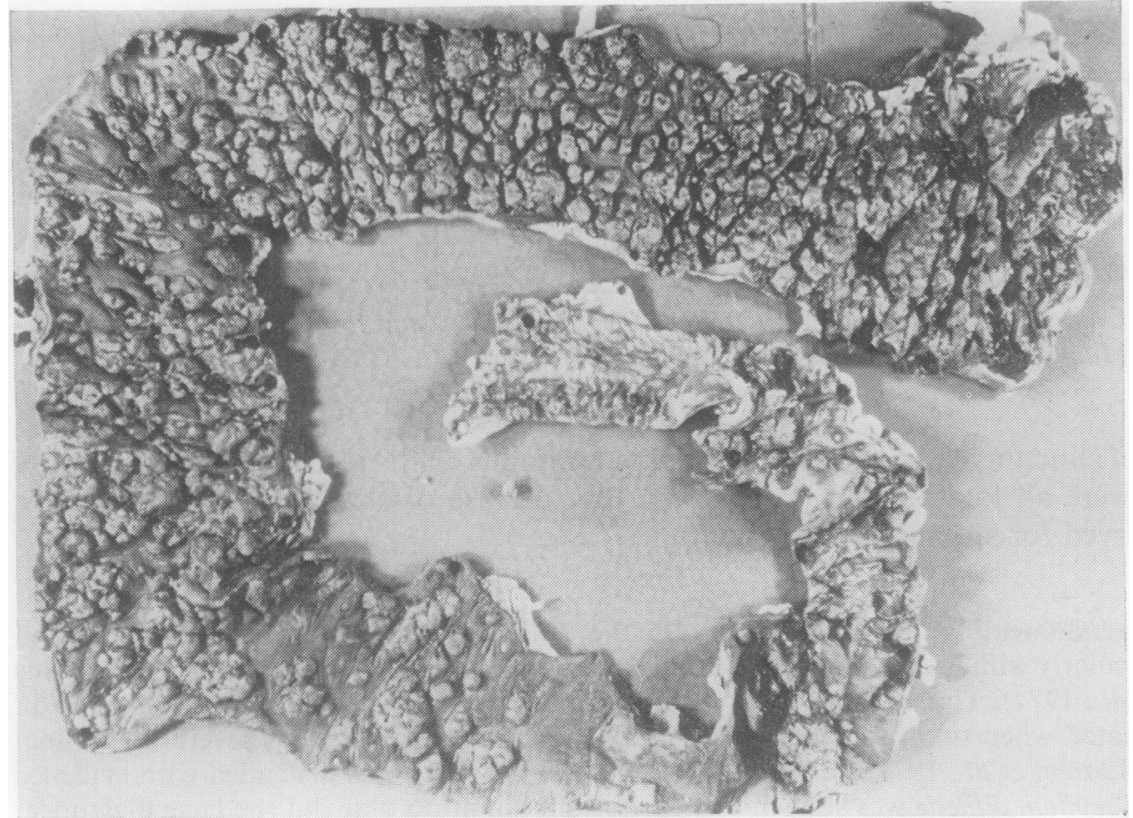

Fig. 1 Case 1. Total colonic involvement by PMC. The caecum is at the top right. The severity of the PMC lessens distally.

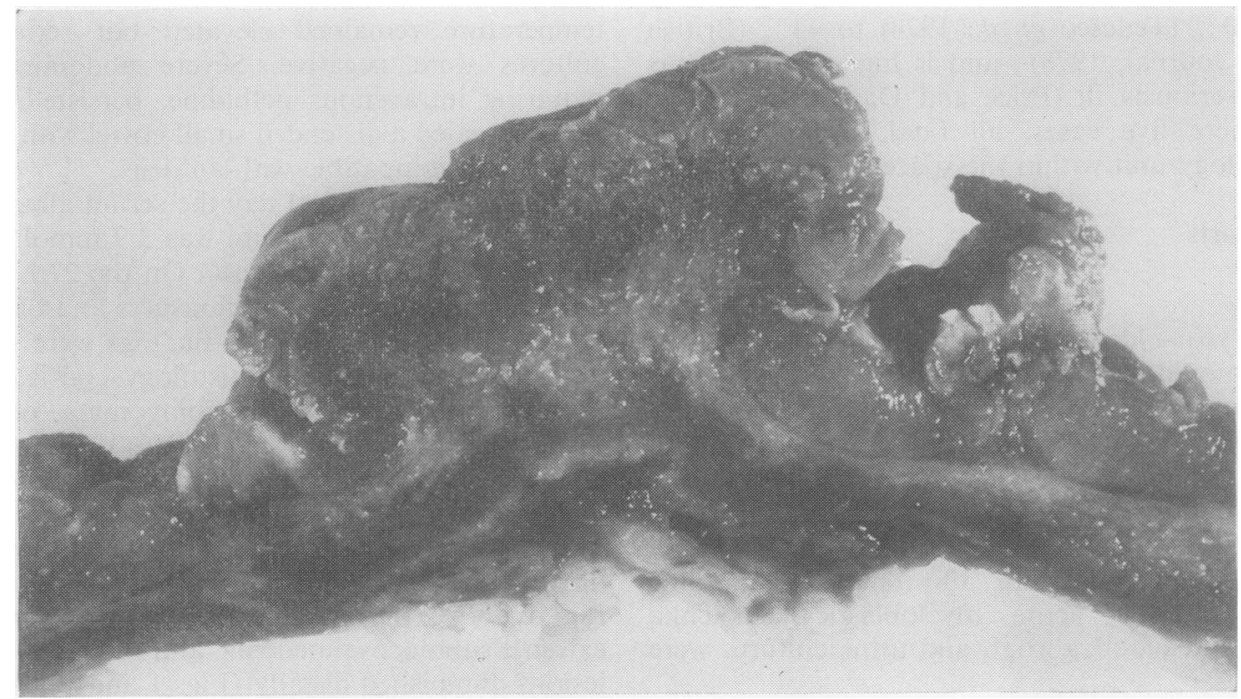

Fig. 2 Case 1. Cross-section of an individual lesion showing successively from above: pseudomembrane, haemorrhagic mucosa, submucosal oedema, and haemorrhagic muscularis propria and submucosa. $(\times 5)$

Blue stains, was greater than in the others in this series. There was a zone of haemorrhage at the junction of the mucosa and submucosa, but vascular thrombosis was not a feature. Cultures and toxin estimations were not performed.
CASE 2

This 30-year-old woman had presented with chronic granulocytic leukaemia (CGL) four years earlier. She responded well to chemotherapy and had a splenectomy while in remission. Before her last 
admission she developed a high platelet count (in excess of $1000 \times 10^{9} / 1$ ) which was partially controlled with ${ }^{32} \mathrm{P}$ and uracil mustard. She was admitted with a temperature of $39^{\circ} \mathrm{C}$ and slight skin purpura. She had sustained superficial bruising in a road traffic accident 14 days before admission.

Investigations: Haemoglobin $6.9 \mathrm{~g} / \mathrm{dl}$, white cells $1.9 \times 10^{9} / 1$, platelets $10 \times 10^{9} / 1$, serum albumin 35 $\mathrm{g} / \mathrm{l}$, serum potassium $3.4 \mathrm{mmol} / \mathrm{l}$. A bone marrow aspiration was unsuccessful and trephine biopsy showed secondary myelofibrosis. Cultures of blood, urine, and throat were negative.

She was transfused with blood and platelets and treated with tobramycin and clindamycin with no resolution of temperature. After four days she developed diarrhoea, which rapidly worsened, and the antibiotics were stopped on the seventh day. The diarrhoea was treated initially with kaolin and morphine mixture and later with codeine phosphate. These had little effect and she produced large quantities of liquid faeces and mucus. In view of her poor clinical condition sigmoidoscopy was not attempted. Stool cultures were negative for pathogens but clostridia were not looked for specifically. She became hypokalaemic $(2.4 \mathrm{mmol} / \mathrm{l})$ and was given intravenous fluids and potassium.

Five days after the onset of diarrhoea she received intravenous cloxacillin and gentamicin because of the persistent pyrexia and she was also supported with leucocytes harvested from a sibling. By the 15th hospital day the serum albumin had fallen to $25 \mathrm{~g} / 1$ and she developed abdominal pain and generalised abdominal tenderness. The next day she became jaundiced and comatose and died 19 days after admission.

At necropsy there was widespread purpura, fibrinous pericarditis, bilateral pleural effusions, ascites, and PMC. The bone marrow showed secondary myelofitrosis. The colonic serosa was blackened by haemorrhage, and the wall was thickened by submucosal oedema. Yellowish-grey plaques of pseudomembrane covered almost the entire mucosal surface with abundant adherent mucus. Microscopically pseudomembrane merged into necrotic or partially necrotic mucosa, the mucosal glands were dilated and lined by flattened cells, and adjacent glands had a hypersecretory pattern. Submucosal oedema was maximal under totally necrotic mucosa, and in one section thrombosed submucosal blood vessels were found.

Cultures of faeces grew clostridial species, including $\mathrm{Cl}$. paraputrificum and $\mathrm{Cl}$. iamosum. $\mathrm{Cl}$. difficile was not grown. Toxin was not sought.

CASE 3

This 41-year-old woman was found to have CGL in 1975. She responded well to treatment and underwent splenectomy. She remained well until early 1978 when she developed thrombocytopenia, which was controlled with uracil mustard and ${ }^{32} \mathrm{P}$.

In July 1978 she became unwell with bone pain and fever and was admitted to hospital in August with severe bone pain, effusions in the knees, and a high fever.

Investigations: Haemoglobin $8.5 \mathrm{~g} / \mathrm{dl}$, white cells $74 \times 10^{9} / 1(10 \%$ blasts $)$, platelets $880 \times 10^{9} / 1$; synovial fluid: no cells or crystals, culture negative; serum potassium $4.3 \mathrm{mmol} / \mathrm{l}$, serum albumin $39 \mathrm{~g} / \mathrm{l}$. Blood, throat, and urine cultures were negative. Bone marrow confirmed blast transformation of CGL.

She was given intravenous cytosine arabinoside to control the bone pain and a five-day course of intravenous clindamycin and gentamicin with a rapid resolution of fever. Two days later she developed profuse diarrhoea which was mucoid and was uncontrolled on codeine phosphate or atropine diphenoxylate mixture (Lomotil). Concurrently with the diarrhoea her pyrexia recurred and this was not controlled by further treatment with intravenous benzylpenicillin and tobramycin or later with carbenicillin and gentamicin. In order to control the leukaemia she received a three-day course of razoxane and cytosine arabinoside, and this resulted in a fall in the white cell count to $13.9 \times 10^{9} / 1$.

The diarrhoea continued unabated, and 17 days after stopping clindamycin she developed ascites and oedema in the lower limbs. The serum albumin fell to $24 \mathrm{~g} / \mathrm{l}$ and the serum potassium to $2.5 \mathrm{mmol} / 1$ despite large intravenous supplements. Her condition continued to deteriorate despite the administration of salt-poor albumin and she developed severe abdominal pain. To relieve this 4 litres of ascitic fluid were removed by paracentesis while she received, concurrently, intravenous albumin. She did not improve, became hypotensive and oliguric, and died three days later.

At necropsy there was moderate oedema of the lower limbs, genitalia, and sacrum, bilateral bronchopneumonia, and $200 \mathrm{ml}$ of straw-coloured ascites. The colon showed diffuse PMC, individual lesions measuring $0.5-1.0 \mathrm{~cm}$ in diameter, abundant adherent mucus, little intervening healthy mucosa, severe submucosal oedema, and a healthy muscularis and serosa. Microscopically the pseudomembrane showed the typical streams of mucin, fibrin, and polymorphs with distended underlying mucosal glands and variable mucosal necrosis (Fig. 3).

Cultures and toxin analysis were not performed.

CASE 4

This woman of 57 was admitted complaining of excessive tiredness and bruising. 


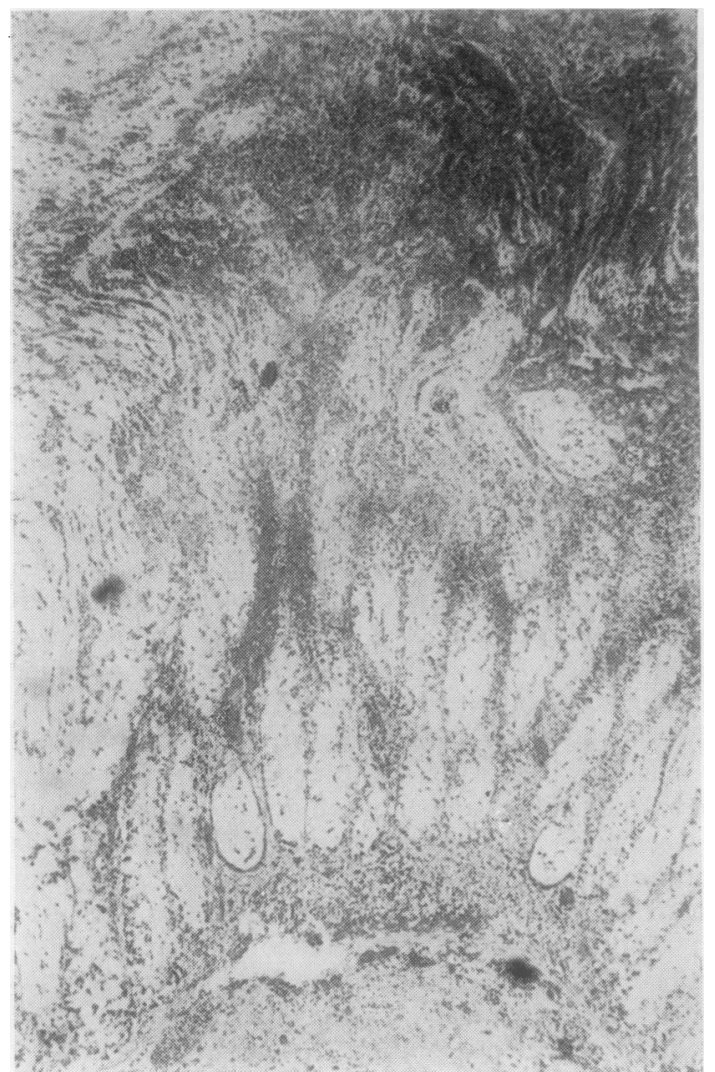

Fig. 3 Mucosal glands are dilated and the cells are flattened. The superficial mucosa is necrotic, and the overlying pseudomembrane is formed of mucus, fibrin, and inflammatory cells, which stream away from the damaged mucosa. (Haematoxylin and eosin $\times 130$ )

Investigations: Haemoglobin $6.6 \mathrm{~g} / \mathrm{dl}$, white cells $8.1 \times 10^{9} / 1$ (32\% blasts), platelets $19 \times 10^{9} / 1$, serum potassium $4.9 \mathrm{mmol} / \mathrm{l}$, serum albumin $38 \mathrm{~g} / \mathrm{l}$, urea $3.9 \mathrm{mmol} / \mathrm{l}$. The bone marrow and blood film showed AML.

She was given a five-day course of daunorubicin, cytosine arabinoside, and thioguanine (DAT) (Rees and Hayhoe, 1978) and three days later became pyrexial. This was thought to be due to an axillary abscess, and in view of her leucopenia (white cells $1.3 \times 10^{9} / 1,12 \%$ neutrophils) treatment was started with intravenous tobramycin and clindamycin. Her temperature settled and the antibiotics were stopped after five days.

Eight days later she developed mild diarrhoea and was not given an antidiarrhoeal agent. Ten days after stopping antibiotics she was noted to have ascites and developed abdominal pain. The serum albumin had fallen to $23 \mathrm{~g} / \mathrm{l}$. The next day she became shocked and oliguric and the urea rose to $19 \mathrm{mmol} / \mathrm{l}$. Despite intensive resuscitative efforts with intravenous steroids, fluids, and antibiotics death occurred on the 25th hospital day.

At necropsy there was generalised purpura, haemorrhagic renal pelves, moderate pulmonary oedema, small pleural effusions, and 3 litres of straw-coloured ascites. The colonic serosa was patchily blackened due to subserosal haemorrhage, and the mucosa showed confluent, yellow pseudomembranes on a haemorrhagic and oedematous submucosa. Apart from an $8 \mathrm{~cm}$ segment nearest the caecum, the distal $80 \mathrm{~cm}$ of ileum was also affected, being covered by sheets of friable black material, and the ileitis gradually diminished with increasing distance from the caecum. Microscopically the colonic pseudomembrane was similar to that of the previous cases and there was no vascular thrombosis. The terminal ileal lesions showed mucosal and submucosal haemorrhage, particularly at the tips of the mucosal folds, and the pseudomembrane was composed of fibrin and bloodclot adherent to th:

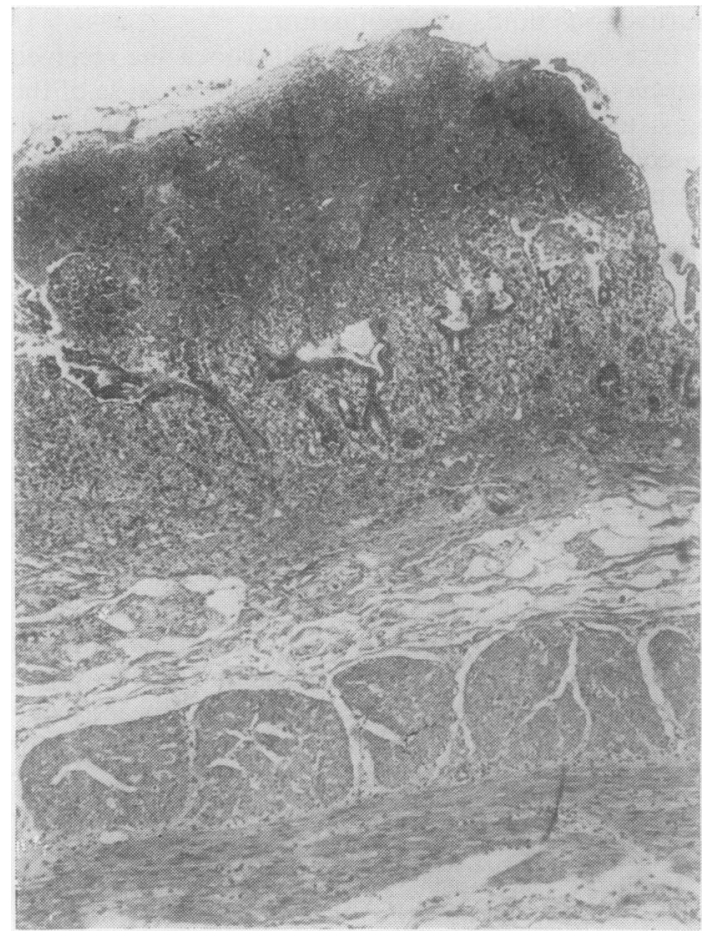

Fig. 4 Case 4. An ileal pseudomembrane composed of fibrin and blood clot incorporating cores of haemorrhagic and necrotic villi. The gland crypts are intact. ( $H$ and $E \times 40)$ 
mucosa and incorporated the cores of necrotic and haemorrhagic villi (Fig. 4). The gland crypts were intact though there was widespread laminal haemorrhage, and occasionally the whole tip of a mucosal fold was haemorrhagic and merged into the pseudomembrane.

The faeces were strongly positive for clostridial toxin, showing cytopathic effect at dilutions in excess of $1: 100$ which was fully neutralised by $\mathrm{Cl}$. sordellii antitoxin (Larson et al., 1977; Larson and Price, 1977). $C l$. welchii and $C l$. paraputrificum were grown from faeces; blood cultures taken on the last day of life grew Klebsiella species and E. coli.

\section{CASE 5}

This 31-year-old woman was admitted with a history of fever and bruising.

Investigations: Haemoglobin $5 \cdot 1 \mathrm{~g} / \mathrm{dl}$, white count $6.6 \times 10^{9} / 1$, serum potassium $4.1 \mathrm{mmol} / \mathrm{l}$, urea $4.7 \mathrm{mmol} / \mathrm{l}$, albumin $34 \mathrm{~g} / \mathrm{l}$. The bone marrow confirmed the diagnosis of AML.

She was transfused with blood and platelets and two days later received a five-day course of DAT. Shortly after this she became febrile and despite negative blood cultures was given intravenous tobramycin and clindamycin in view of her low white cell count $\left(1.5 \times 10^{9} / 1,9 \%\right.$ neutrophils). Her temperature responded well but on the fifth and final day of antibiotics she developed diarrhoea. This became profuse and intractable and did not respond to oral loperamide (Immodium). The faeces contained large quantities of mucus and occasional blood. Five days after the onset of diarrhoea she became pyrexial again and was given intravenous gentamicin and carbenicillin as well as leucocytes from a sibling. She also received a further course of cytotoxic chemotherapy.

Nine days after the onset of diarrhoea her serum potassium had fallen to $2.0 \mathrm{mmol} / 1$ despite large intravenous supplements. She then developed slight abdominal pain, ascites, and ankle oedema, and the serum albumin had dropped to $20 \mathrm{~g} / \mathrm{l}$. This was corrected with intravenous salt-poor albumin. Sigmoidoscopy was attempted but was impossible due to masses of liquid faeces and mucus. She was given oral vancomycin but her condition continued to deteriorate and she died three days later, three weeks after admission.

At necropsy there was ankle oedema, lower lobe pulmonary oedema, small pleural effusions, and 1.5 litres of ascites. The large intestine showed marked serosal congestion and diffuse pseudomembranous colitis with adherent mucus. The faeces were liquid. Microscopically the appearances were similar to those of case 3, but in addition there was mucosal and submucosal haemorrhage and fibrin deposition locally in mucosal and submucosal blood vessels in association with totally necrotic mucosa.

Postmortem faeces were strongly positive for clostridial toxin, showing cytopathic effect at dilutions in excess of $1: 100$, which was entirely neutralised by $\mathrm{Cl}$. sordellii antitoxin. Cultures grew clostridial species which died on subculture.

\section{Discussion}

These patients, with one exception (case 1), closely fitted the clinical description given of PMC with diarrhoea, fever, hypokalaemia, hypoalbuminaemia, and shock (Cammerer et al., 1976). Case 1 was atypical because of the absence of diarrhoea and hypokalaemia, and at necropsy there was no adherent mucus. Four of the patients were neutropenic and were unable to respond with a leucocytosis, and this may have been an adverse prognostic feature. We feel that although the patients had serious underlying disease, the PMC was an important contributory factor to death. In particular, at least one of the two patients with acute myeloblastic leukaemia might reasonably have been expected to attain remission following DAT (Rees and Hayhoe, 1978).

It has been recognised for some time that PMC is more commonly fatal in those with serious underlying illnesses (Price and Davies, 1977), but this is the first series of fatal cases reported in leukaemic patients although sporadic cases have been reported elsewhere (Goulston and McGovern, 1965; Kappas et al., 1978). During the period of eight months in which these five cases occurred, a total of 40 pyrexial episodes in 37 patients ( 24 female, 13 male) were treated. Clindamycin combined with an aminoglycoside antibiotic has been the standard treatment for pyrexial episodes in neutropenic patients in this unit for four years. Over this period these have been the only cases of PMC encountered, and although it is conceivable that earlier cases had been missed, a clinical trial using gentamicin combined with clindamycin in 50 patients in this unit in 1976 did not produce a single case despite a high index of suspicion (Wilkinson et al., 1977). Clustering of PMC cases has been noted previously (British Medical Journal, 1978) and supports Price and Larson's (1979) suggestion that the disease may be due to cross-infection by $\mathrm{Cl}$. difficile. However, this organism was not isolated from the stools of either patient from whom clostridia were successfully cultured though the characteristic toxin was present in high concentration in the two patients in whom it was sought. The five patients were at some time nursed on the same open ward although as their condition deteriorated they were moved to side- 
wards. They were not barrier-nursed. Cases 1 and 2 developed concurrently as did cases 4 and 5 .

This series also supports the suggestion that PMC is more common in women (Keusch and Present, 1976) as none of the 13 men treated during this period developed PMC.

In earlier series of pseudomembranous enterocolitis (Pettet et al., 1954; Kay et al., 1958) small intestinal involvement was a prominent feature, but these series appear to include mainly ischaemic and infectious disease rather than PMC due to clostridial toxin. In this context it is of interest that our case 4 showed ileal involvement, a feature that seems to be very uncommon in PMC but has been recorded previously (Schapiro and Newman, 1973).

In retrospect, the use of specific antidiarrhoeal agents may have been unwise as there is now a growing body of evidence that they may be harmful in PMC (Lancet, 1977; Pittmann, 1979). One patient (case 5) received vancomycin late in the course of her illness without apparent benefit but there is now definite evidence that its use is beneficial in PMC (Tedesco et al., 1978). Pashby et al. (1979) have also found that oral metronidazole may be useful in the treatment of PMC but this view is disputed by Mogg and his colleagues (1979).

Experience with these cases has resulted in a change in the antibiotic policy for febrile neutropenic patients in this department, and clindamycin is no longer used. Since PMC is more severe in patients who are already seriously ill, the use of clindamycin in this situation should be reserved for specific indications and consideration should be given to oral prophylaxis with vancomycin.

We thank Dr I. W. Delamore for permission to report patients under his care and Drs A. B. Price and H. E. Larson, Northwick Park Hospital, for the toxin analysis. We also thank Drs A. R. Mainwaring, A. Ahmed, and I. Gupta for providing necropsy material.

\section{References}

Bartlett, J. G., Chang, T. W., Gurwith, M., Gorbach, S. L., and Onderdonk, A. B. (1978a). Antibioticassociated pseudomembranous colitis due to toxinproducing clostridia. New England Journal of Medicine, 298, 531-534.

Bartlett, J. G., Moon, N., Chang, T. W., Taylor, N., and Onderdonk, A. B. (1978b). Role of Clostridium difficile in antibiotic-associated pseudomembranous colitis. Gastroenterology, 75, 778-782.

Bartlett, J. G., Onderdonk, A. B., Cisneros, R. L., and Kasper, D. L. (1977). Clindamycin-associated colitis due to a toxin-producing species of Clostridium in hamsters. Journal of Infectious Diseases, 136, 701-705.

British Medical Journal (1978). Antibiotic associated colitis: a progress report (Leading article). British Medical Journal, 1, 669-671.

Cammerer, R. C., Anderson, D. L., Boyce, H. W., Jr., and Burdick, G. E. (1976). Clinical spectrum of pseudomembranous colitis. Journal of the American Medical Association, 235, 2502-2505.

Crowther, D., Powles, R. L., Bateman, C. J. T., Beard, M. E. J., Gauci, C. L., Wrigley, P. F. M., Malpas, J. S., Hamilton-Fairley, G., and Bodley-Scott, R. (1973). Management of adult acute myelogenous leukaemia. British Medical Journal, 1, 131-137.

George, R. H., Symonds, J. M., Dimock, F., Brown, J. D., Arabi, Y., Shinagawa, N., Keighley, M. R. B., Alexander-Williams, J., and Burdon, D. W. (1978). Identification of Clostridium difficile as a cause of pseudomembranous colitis. British Medical Journal, 1, 695.

Goulston, S. J. M., and McGovern, V. J. (1965). Pseudomembranous colitis. Gut, 6, 207-212.

Kappas, A., Shinagawa, N., Arabi, Y., Thompson, H., Burdon, D.W., Dimock, F., George, R. H., AlexanderWilliams, J., and Keighley, M. R. B. (1978). Diagnosis of pseudomembranous colitis. British Medical Journal, 1, 675-678.

Kay, A. W., Richards, R. L., and Watson, A. J. (1958). Acute necrotizing (pseudomembranous) enterocolitis. British Journal of Surgery, 46, 45-57.

Keusch, G. T., and Present, D. H. (1976). Summary of a workshop on clindamycin colitis. Journal of Infectious Diseases, 133, 578-587.

Lancet (1977). Pseudomembranous enterocolitis (Editorial). Lancet, 1, 839-840.

Larson, H. E., Parry, J. V., Price, A. B., Davies, D. R., Dolby, J., and Tyrrell, D. A. J. (1977). Undescribed toxin in pseudomembranous colitis. British Medical Journal, 1, 1246-1248.

Larson, H. E., and Price, A. B. (1977). Pseudomembranous colitis: presence of clostridial toxin. Lancet, 2, 1312-1314.

Mogg, G. A. G., Burdon, D. W., and Keighley, M. (1979). Oral metronidazole in Clostridium difficile colitis (Letter). British Medical Journal, 2, 335.

Pashby, N. L., Bolton, R. P., and Sherriff, F. J. (1979). Oral metronidazole in Clostridium difficile colitis. British Medical Journal, 1, 1605-1606.

Pettet, J. D., Baggenstoss, A. H., Dearing, W. H., and Judd, E. S., Jr. (1954). Postoperative pseudomembranous enterocolitis. Surgery, Gynaecology and Obstetrics, 98, 546-552.

Pittmann, F. E. (1979). Antibiotic-associated colitis-an update. Adverse Drug Reaction Bulletin, 75, 268-271.

Price, A. B., and Davies, D. R. (1977). Pseudomembranous colitis. Journal of Clinical Pathology, 30, 1-12.

Price, A. B., and Larson, H. E. (1979). Pseudomembranous colitis (Letter). Lancet, 1, 443.

Rees, J. K. H., and Hayhoe, F. G. J. (1978). D.A.T. (Daunorubicin, cytarabine, 6-thioguanine) in acute myeloid leukaemia (Letter). Lancet, 1, 1360-1361.

Schapiro, R. L., and Newman, A. (1973). Acute enterocolitis: a complication of antibiotic therapy. Radiology, 
108, 263-268.

Tedesco, F. J., Barton, R. W., and Alpers, D. H. (1974). Clindamycin-associated colitis. Annals of Internal Medicine, 81, 429-433.

Tedesco, F., Markham, R., Gurwith, M., Christie, D., and Bartlett, J. G. (1978). Oral vancomycin for antibioticassociated pseudomembranous colitis. Lancet, 2 , 226-228.

Wilkinson, P. M., Gorst, D. W., Tooth, J. A., and
Delamore, I. W. (1977). The management of fever in blood dyscrasias: results of a prospective controlled trial of a prescribing aid for gentamicin. Journal of Antimicrobial Chemotherapy, 3, 297-303.

Requests for reprints to: Dr D. W. Milligan, Manchester Royal Infirmary, Oxford Road, Manchester M13 9WL, UK.

\section{The November 1979 Issue}

\section{THE NOVEMBER 1979 ISSUE CONTAINS THE FOLLOWING PAPERS}

Cytological diagnosis of virus-infected cells in Papanicolaou smears and its application in clinical practice D. v. COLEMAN

Neonatal necrotising enterocolitis R. A. TAIT AND W. F. KEALY

Pulmonary carcinoid tumours: a comparative regional study T. COONEY, E. C. SWEENEY, AND D. LUKE

Immunoblastic lymphadenopathy: evolution into immunoblastic sarcoma S. BANIK, R. L. WARD, AND P. S. HASLETON

Sea blue histiocytosis in a patient with chronic non-neuropathic Niemann-Pick disease N. DE $W$. HURST, G. T. N. BESLEY, N. D. C. FINLAYSON, AND A. C. PARKER

Carcinoma in situ of the male breast F. M. COLE AND A. H. QIZILBASH

Circulating and deposited immune complexes in renal disease and their clinical correlation $\mathbf{S}$. $\mathbf{L}$. COHEN, C. FISHER, J. F. MOWBRAY, A. HOPP, AND J. BURTON-KEE

Serum immunoglobulins in a rural and an urban population of Greece with special reference to immunoglobulin A J. ECONOMIDOU, O. MANOUSOS, D. TRICHOPOULOS, J. TRIANTAPHYLLIDIS, T. TSICRICAS, AND G. MERIKAS

Clinical pathology—déjà-vu? GEORGE W. PENNINGTON

Interference of cefoxitin in the creatinine estimation and its clinical relevance S. R. DURHAM, A. H. C. BIGNELL, AND R. WISE
Changes in the heparin neutralising activity of platelet poor plasma after immunisation I. A. BAKER, C. H. L. HOWELLS, AND J. R. O'BRIEN

Early detection of Chlamydia trachomatis using fluorescent, DNA binding dyes $\mathrm{S}$. H. SALARI AND M. E. WARD

Rapid diagnosis of anaerobic infections by gas-liquid chromatography S. LADAS, G. ARAPAKIS, H. MALAMOU-LADAS, G. PALIKARIS, AND A. ARSENI

Identification of viridans streptococci on the Minitek Miniaturised Differentiation System YVETTE HOLLOWAY, MARIJKE SCHAAREMAN, AND J. DANKERT

Action and interaction of penicillin and gentamicin on enterococci FRANCISCO SORIANO AND DAVID GREENWOOD

A sensitive single reverse passive haemagglutination test for detecting both HBsAg and anti-HBs J. A. J. BARBARA, P. J. HARRISON, D. R. HOWELL, T. E. CLEGHORN, D. S. DANE, MOYA BRIGGS, AND C. H. CAMERON

Ethylene oxide sterilisation-is it safe? E. H. GILLESPIE, J. M. JACKSON, AND G. R. OWEN

Technical method

An integrated two-test automated syphilis screening system D. E. MACFARLANE

Letters to the Editor

Book reviews

Copies are still available and may be obtained from the PUBLISHING MANAGER, BRITISH MEDICAL ASSOCIATION, TAVISTOCK SQUARE, LONDON WC1H 9JR, price $£ 3.00$, including postage 